Article

\title{
Towards Blue Long-Lasting Luminescence of Eu/Nd-Doped Calcium-Aluminate Nanostructured Platelets via the Molten Salt Route
}

\author{
Rocío E. Rojas-Hernandez ${ }^{1,2, *(0)}$, Fernando Rubio-Marcos ${ }^{1,3}{ }^{\oplus}$, Aida Serrano ${ }^{1}(\mathbb{D}$, \\ Eduardo Salas ${ }^{4,5}{ }^{-}$, Irina Hussainova ${ }^{2}$ and José Francisco Fernandez ${ }^{1}$ \\ 1 Electroceramic Department, Instituto de Cerámica y Vidrio, CSIC, Kelsen 5, 28049 Madrid, Spain; \\ frmarcos@icv.csic.es (F.R.-M.); aida.serrano@icv.csic.es (A.S.); jfernandez@icv.csic.es (J.F.F.) \\ 2 Department of Materials Engineering, Tallinn University of Technology, Ehitajate 5, 19180 Tallinn, Estonia; \\ irina.hussainova@taltech.ee \\ 3 Escuela Politécnica Superior, Universidad Antonio de Nebrija, C/Pirineos, 55, 28040 Madrid, Spain \\ 4 Spanish CRG BM25 SpLine beamline, The European Synchrotron, 38043 Grenoble, France; \\ edusc22@gmail.com \\ 5 Instituto de Ciencia de Materiales de Madrid, CSIC, 28049 Madrid, Spain \\ * Correspondence: rociorojas@icv.csic.es or rocio.rojas@taltech.ee
}

Received: 22 August 2019; Accepted: 14 October 2019; Published: 16 October 2019

\begin{abstract}
Calcia-alumina binary compounds doped with rare earths and some transition metals cations show persistent luminescence from the visible to the infrared range. Specifically, the blue light can be obtained through the $\mathrm{Eu}^{2+}$ activator center in a potential host, such as dodecacalcium hepta-aluminate $\left(\mathrm{Ca}_{12} \mathrm{Al}_{14} \mathrm{O}_{33}\right)$ and monocalcium aluminate $\left(\mathrm{CaAl}_{2} \mathrm{O}_{4}\right)$. By doping with $\mathrm{Nd}^{3+}$, the persistent luminescence can be substantially prolonged; for this reason, the Eu/ $\mathrm{Nd}$ pair is a potential choice for developing long-lasting blue luminescence. Herein, the phase evolution of the calcia-alumina system via molten salt synthesis is reported as a function of the synthesis temperature and the atmospheric environment. The fraction of $\mathrm{CaAl}_{2} \mathrm{O}_{4}$ phase increases when the temperature is higher. Synthesized microparticles of platelet-type morphology represent isolated nanostructured ceramic pieces. Under visible light, the particles are white. This indicates that the followed process solves the dark-gray coloring of phosphor when is synthesized in a reduced atmosphere at high temperature. As regards the synthesis mechanism, which is assisted by the molten flux, the dissolution-diffusion transport process is promoted at the surface of the alumina microparticles. In fact, the emission intensity can be modulated through the phase of the Eu-doped calcium-aluminate discrete platelets synthesized. Consequently, the photoluminescence intensity depends also on the oxidation state of the Eu ion. X-ray absorption near-edge structure and photoluminescence measurements corroborate the Eu reduction and the grain coarsening with the enhancement of the blue emission. The doped phosphors with Eu/Nd show a broad and strong absorption in the region of 320-400 $\mathrm{nm}$ and a broad emission band at around $440 \mathrm{~nm}$ when they are excited in this absorption range. From a broader perspective, our findings prove that the $\mathrm{Ca}_{12} \mathrm{Al}_{14} \mathrm{O}_{33}$ and $\mathrm{CaAl}_{2} \mathrm{O}_{4}$ phases open new opportunities for research into the design of blue long-lasting emitters for a wide range of fields from ceramic to optoelectronic materials.
\end{abstract}

Keywords: calcium-aluminates; molten salt method; persistent luminescence; XANES; phosphor; rare-earth 


\section{Introduction}

Research on rare earth luminescent materials has been stimulated over the last decade by several important industrial applications, such as bioimaging and energy harvesting. There is a great demand for rare earth-doped oxide materials with excellent luminous efficiency and high thermal stability. Specifically, alkaline-earth metal aluminates are oxides that fulfill these requirements [1], as such materials have the unique advantages of high quenching temperature, corrosion resistance, low cost and non-toxicity, which makes them economically attractive. Nowadays, not only the emission of light in a fixed range (Ultraviolet, (UV), to Near Infrared Region, (NIR)) is required, but also the capability of materials to act as an optical storage is needed. These materials should emit after the removal of the activation light source. A wide range of applications, including but not limited to, devices for a night vision, optical storage, solar energy, and in-vivo imaging, is opened for such kinds of these long-lasting luminescent materials. The well-known persistent compound $\mathrm{SrAl}_{2} \mathrm{O}_{4}: \mathrm{Eu}, \mathrm{Dy}$ can emit in the green color for up to $24 \mathrm{~h}[2,3]$. Although the research is focused mainly upon green emission due to the large sensitivity in this region of the human eye (luminous efficacy) in light and dark conditions, the persistent emission other wavelength ranges (blue or red light emission) is also desirable.

There are specific applications that demand persistent blue and red phosphors with comparable emission durations to those of green ones. It is worth remarking that UV-chip or UV light can activate the phosphors, but the sunlight activation can represent a great achievement due to the reduction of energy consumption. Therefore, evaluation of the efficiency of the persistent phosphors activated by natural sunlight is very much in demand.

The persistent blue-emitters materials have usually been based upon the strontia-alumina (SrO- $\mathrm{Al}_{2} \mathrm{O}_{3}$ ) system, such as $\mathrm{Sr}_{2} \mathrm{Al}_{6} \mathrm{O}_{11}, \mathrm{Sr}_{4} \mathrm{Al}_{14} \mathrm{O}_{25}, \mathrm{SrAl}_{4} \mathrm{O}_{7}$, etc. [1]. The best candidate for the blue long persistent emitter is the outstanding $\mathrm{CaAl}_{2} \mathrm{O}_{4}: \mathrm{Eu}^{2+}$ [1], where co-doping it with $\mathrm{Nd}^{3+}$ enhances the afterglow duration due to the depth increment [4]. Although the photoluminescence (PL) mechanism has not yet been established by consensus, the studies indicate that the oxygen vacancies are the main trap centers for the mono-doped $(\mathrm{Eu})$ host, and the co-doping with $\mathrm{Nd}^{3+}$ increases the electron carriers and feeds deeper traps $[5,6] . \mathrm{CaAl}_{2} \mathrm{O}_{4}$ and $\mathrm{Ca}_{12} \mathrm{Al}_{14} \mathrm{O}_{33}$ phases are the most studied ones; they have been synthesized by different methods including combustion, sol-gel, co-precipitation and solid-state approaches [6-9]. However, the produced materials usually contain undesirable phases such as $\mathrm{CaAl}_{4} \mathrm{O}_{7}$ and $\mathrm{Ca}_{3} \mathrm{Al}_{2} \mathrm{O}_{6}$. The reaction processes are not trivial in the $\mathrm{CaO}-\mathrm{Al}_{2} \mathrm{O}_{3}$ system, and many intermediated phases can be generated [8]. The processing of these materials requires two or three steps at a high temperature, a quite long reaction time and annealing in a reductive atmosphere. Moreover, the particles obtained by these routes tend to agglomerate, forming small clusters with non-uniform shapes and sizes $[8,10]$, which is not suitable for practical applications.

Our previous study related to the synthesis of the long-lasting green luminescent materials based on $\mathrm{SrAl}_{2} \mathrm{O}_{4}$ : Eu, Dy has demonstrated that the starting alumina plays a key role in the kinetics of the reaction when a molten flux is employed. This reactivity is modulated by the nature, size, and morphology of the precursor. It is possible to synthesize the green emitters, $\mathrm{SrAl}_{2} \mathrm{O}_{4}$ : Eu, Dy, with a pseudo-spherical morphology and a particle size $\leq 0.5 \mu \mathrm{m}$ when a sub-micron $\mathrm{Al}_{2} \mathrm{O}_{3}\left(0.1 \mu \mathrm{m} \mathrm{Al}_{2} \mathrm{O}_{3}\right)$ is employed [11,12]. However, the growth of $\mathrm{SrAl}_{2} \mathrm{O}_{4}: \mathrm{Eu}$, Dy sub-micron particles on the surface of the hexagonal platelets of $6 \mu \mathrm{m} \mathrm{Al}_{2} \mathrm{O}_{3}$ is promoted when a larger alumina particle, $6 \mu \mathrm{m} \mathrm{Al}_{2} \mathrm{O}_{3}$, is employed, modifying the reaction pathway and leading to a different reaction evolution. One of the advantages of the platelets obtained is their thickness of ca. $\leq 1 \mu \mathrm{m}$, which is suitable for potential applications. Here, as the alumina precursor, $6 \mu \mathrm{m} \mathrm{Al}{ }_{2} \mathrm{O}_{3}$ particles were employed to study the reaction pathway to synthesize calcium aluminate luminescent compounds, obtaining persistent emission in the blue range. A key parameter in the molten salt method is the nature of the molten salt flux. There are several requirements for the nature of the salt that should be fulfilled, among them, there is an adequate melting point (m.p.), good chemical stability, ease of washability, and cots effectiveness. 
The phase formation of the desired $\mathrm{CaAl}_{2} \mathrm{O}_{4}$ is expected to occur at high temperatures; for this reason the eutectic mixture of $\mathrm{NaCl}-\mathrm{KCl}$ (the melting point of which is $659^{\circ} \mathrm{C}$ ) was selected, also taking into consideration the high solubility in glycerol of chlorides [13], which may be important for easy removal of the $\mathrm{NaCl}-\mathrm{KCl}$ mixture if the salts remain during the synthesis treatment, avoiding the water exposure.

Herein, we present a practically scalable approach for the synthesis of blue emitters based on $\mathrm{Ca}_{12} \mathrm{Al}_{14} \mathrm{O}_{33}$ and $\mathrm{CaAl}_{2} \mathrm{O}_{4}$. Through this novel method, we have found a linked relationship between the phase composition and the photoluminescence intensity. These results open prospects for a molten salt route to be considered as a promising technique for the preparation of complex oxide ceramics such as aluminates.

\section{Materials and Methods}

\subsection{Synthesis}

The calcium aluminates $(\mathrm{CAO})$ particles were produced by a molten salt-assisted route. The starting materials were aluminum oxide (aka alumina, $\mathrm{Al}_{2} \mathrm{O}_{3}$ ) (Almatis, Paris, France, Specific Surface Area, BET: $13 \mathrm{~m}^{2} / \mathrm{g}$, average particle size, $\left.\mathrm{d}_{50 \sim} 6 \mu \mathrm{m}\right)$, calcium carbonate $\left(\mathrm{CaCO}_{3}\right)$ (Merck, Burlington, $\mathrm{MA}$, USA, 99.9\%, $\mathrm{d}_{50} \sim 1.1 \mu \mathrm{m}$ ), europium(III) oxide $\left(\mathrm{Eu}_{2} \mathrm{O}_{3}\right)$, (Metal Rare Earth Limited, Shenzhen, China, $99.5 \%, \mathrm{~d}_{50} \sim 3.8 \mu \mathrm{m}$ ) and neodymium(III) oxide or neodymium sesquioxide $\left(\mathrm{Nd}_{2} \mathrm{O}_{3}\right)$ (Rare Earth Limited Shenzhen, China, $\left.99.5 \%, \mathrm{~d}_{50} \sim 3.1 \mu \mathrm{m}\right)$. The stoichiometric mixture of raw materials to obtain the $\mathrm{Ca}_{1-x-y} \mathrm{Eu}_{x} \mathrm{Nd}_{y} \mathrm{Al}_{2} \mathrm{O}_{4}$ composition with $x=0.02$ and $y=0.01$ is used. The precursors were dried at $120{ }^{\circ} \mathrm{C}$ for $1 \mathrm{~h}$ before dry homogenization by grinding in a $60 \mathrm{~cm}^{3}$ nylon container for $20 \mathrm{~min}$ by using a turbula-type mixer at $50 \mathrm{rpm}$ with zirconium dioxide (aka zirconia, $\mathrm{ZrO}_{2}$ ), balls of $0.5 \mathrm{~mm}$ diameter. The mixed CAO and CAO: $\mathrm{Eu}^{2+}, \mathrm{Nd}^{3+}$ powders were then annealed at temperatures in the range of 1000 to $1400{ }^{\circ} \mathrm{C}$ in a tube furnace in an air atmosphere and under a $90 \mathrm{~N}_{2}-10 \mathrm{H}_{2}$ reducing atmosphere, respectively, and finally sieved by using a $100 \mu \mathrm{m}$ sieve.

\subsection{Structural and Microstructural Characterization}

The crystalline phases were characterized by X-ray diffraction (XRD, D8, Bruker Corporation, Billerica, MA, USA) using a Lynx Eye detector and $\mathrm{Cu} \mathrm{K} \alpha_{1,2}$ radiation. The crystallite size $(D)$ of the powders can be estimated from the full width at half maximum of the diffraction peak by the Scherrer Equation:

$$
D=\frac{K \lambda}{B \cos \theta}
$$

where $\lambda$ is the $X$-ray wavelength, B the half maximum of the diffraction peak, $\theta$ is the angle of diffraction, and using a shape factor $(K)$ of 0.9 .

Particle size distribution measurements of the phosphor powders were performed by laser diffraction (Mastersizer S, Malvern, Worcestershire, UK). The morphology of powders was evaluated using secondary electron images of a field emission scanning electron microscopy (FE-SEM, Hitachi S-4700, Marunouchi, Chiyoda-ku, Tokyo, Japan). The average grain size of the calcium aluminate phases formed during the thermal treatment was calculated from FE-SEM micrographs by an image processing and analysis program (Leica Qwin, Leica Microsystems Ltd., Cambridge, England) considering more than 50 grains in each measurement.

Room temperature X-ray absorption near-edge structure spectroscopy (XANES) measurements of powders at the $\mathrm{Eu} \mathrm{L}_{3}$ edge were performed in fluorescence mode detection at $45^{\circ}$ incidence at the Spanish CRG beamline BM25A (SpLine) at The European Synchrotron (The ESRF), in Grenoble (France). The signal was measured using a 13 element Si (Li) solid-state detector from e2V Scientific Instruments ( Sirius House, Watery Lane, Wooburn Green, High Wycombe, Buckinghamshire, UK). The conclusive spectra represent an average of three X-ray absorption spectroscopy (XAS) scans. The XAS data were analyzed using ATHENA software (Demeter 0.9.26). [14] 


\subsection{Luminescent Characterization}

The excitation and emission spectra of the synthesized CAO particles were recorded using a spectrofluorometer (Fluorolog ${ }^{\circledR}-3$, HORIBA Jobin Yvon, Neuhofstraße 9, 64625 Bensheim, Germany) equipped with a $450 \mathrm{~W}$ xenon arc lamp as the light source at room temperature. The afterglow decay curves were measured after irradiating the CAO particles with Ultraviolet, (UV) light at $365 \mathrm{~nm}$ for $10 \mathrm{~min}$.

\section{Results \& Discussion}

This section may be divided by subheadings. It should provide a concise and precise description of the experimental results, their interpretation as well as the experimental conclusions that can be drawn.

\subsection{Understanding the Phase Composition in $\mathrm{CaO}-\mathrm{Al}_{2} \mathrm{O}_{3}$ System as a Function of the Temperature and Atmosphere Conditions}

As a first approximation, we evaluated the vast synthesis conditions to facilitate the formation of the desired crystalline structure. For this, the CAO phosphors were synthesized employing the molten salt method by being heated from 1000 to $1400{ }^{\circ} \mathrm{C}$ for $2 \mathrm{~h}$ in an air atmosphere, employing a salt/CAO molar ratio of $3: 1$ and an $\mathrm{Al}_{2} \mathrm{O}_{3} / \mathrm{CaO}$ ratio of 1 , using alumina of an average particle size $\mathrm{d}_{50 \sim} 6 \mu \mathrm{m}$. Regarding the amount of salt to be used, it is usually comprised between 80 and $120 \%$ in the weight of the reactant mixture, or using molar ratio salt/complex oxide $(S / O), S / O=1: 1,3: 1,4: 1,5: 1$ or 20:1 [15]. After an experiment series, we found that the ratio 3:1 offers the most suitable synthesis conditions, analogously to synthesis for the $\mathrm{SrAl}_{2} \mathrm{O}_{4}$ phosphor.

Figure 1 shows the XRD pattern of the powder synthesized at $1000,1100,1200$ and $1400{ }^{\circ} \mathrm{C}$ in the air atmosphere. At $1000{ }^{\circ} \mathrm{C}$, the XRD shows characteristic peaks of the $\mathrm{Ca}_{12} \mathrm{Al}_{14} \mathrm{O}_{33}$ cubic polymorph, whose pattern is characterized by four peaks centered in the $2 \theta$ axis at $18.11^{\circ}, 27.82^{\circ}, 33.39^{\circ}$ and $41.20^{\circ}$, ascribed to the (211), (321), (420), (521) facet diffraction of the cubic, and matched with the $\mathrm{Ca}_{12} \mathrm{Al}_{14} \mathrm{O}_{33}$ standard values given in JCPDS (No. 09-0413 or 70-2144) and their coexistence with the $\mathrm{NaCl}$ (JCPDF file 72-1668) and $\mathrm{KCl}$ (JCPDF file 76-3376) phases. From the $\mathrm{CaO}-\mathrm{Al}_{2} \mathrm{O}_{3}$ diagram [16], the $\mathrm{Ca}_{12} \mathrm{Al}_{14} \mathrm{O}_{33}$ phase has the lowest forming temperature, around $1400{ }^{\circ} \mathrm{C}$. Applying the molten salt synthesis, this forming temperature can be reduced down to be around $1000{ }^{\circ} \mathrm{C}$, as is shown in Figure 1. In addition, the XRD reveals the presence of another phase, which could be identified as $\mathrm{Al}_{2} \mathrm{O}_{3}$ (JCPDF file 73-1512). The intensity of the XRD peaks of the salt decreases with an increase in temperature, due to its vaporization during the thermal treatment. As commented above, the melting point of the eutectic mixture is observed at $659{ }^{\circ} \mathrm{C}$; however, the remaining salts could be related to the presence of pure salts into the melt. In theory, the $100 \%$ weight loss of the eutectic mixture occurs at ca. $1010^{\circ} \mathrm{C}$, but a shift to a higher temperature is expected when other compounds are added into the system, as it has already reported in a previous work [12].

At $1100{ }^{\circ} \mathrm{C}$, the main phase $\mathrm{Ca}_{12} \mathrm{Al}_{14} \mathrm{O}_{33}$ coexists with the monoclinic $\mathrm{CaAl}_{2} \mathrm{O}_{4}$ phase (JCPDS 70-0134) characterized by the diffraction peaks at $2 \theta=18.99^{\circ}, 30.14^{\circ}, 35.42^{\circ}$, and $37.179^{\circ}$, attributed to the (-112), (220), (006), (313) crystal facets. At $120{ }^{\circ} \mathrm{C}$, the amount of monoclinic $\mathrm{CaAl}_{2} \mathrm{O}_{4}$ phase increases, reaching the maximum of $\mathrm{CaAl}_{2} \mathrm{O}_{4}$ fraction at $1400{ }^{\circ} \mathrm{C}$. Taking into account the reaction mechanism established previously [12], the most probable origin of the rest of these raw materials can be related to an unreacted $\mathrm{Al}_{2} \mathrm{O}_{3}$ core. From these observations, it can be stated that a thermal treatment at $1000{ }^{\circ} \mathrm{C}$ produces the $\mathrm{Ca}_{12} \mathrm{Al}_{14} \mathrm{O}_{33}$ compound, and the $\mathrm{CaAl}_{2} \mathrm{O}_{4}$ compound is synthesized at $1400{ }^{\circ} \mathrm{C}$. Between 1000 and $1400{ }^{\circ} \mathrm{C}$, there is a coexistence of both phases. In the case of calcium aluminate host materials, it is difficult to produce the pure phase products owing to the generation of many phases together during the preparation, so the presence of the mixed phases may influence the luminescence performance of rare earth compounds. 


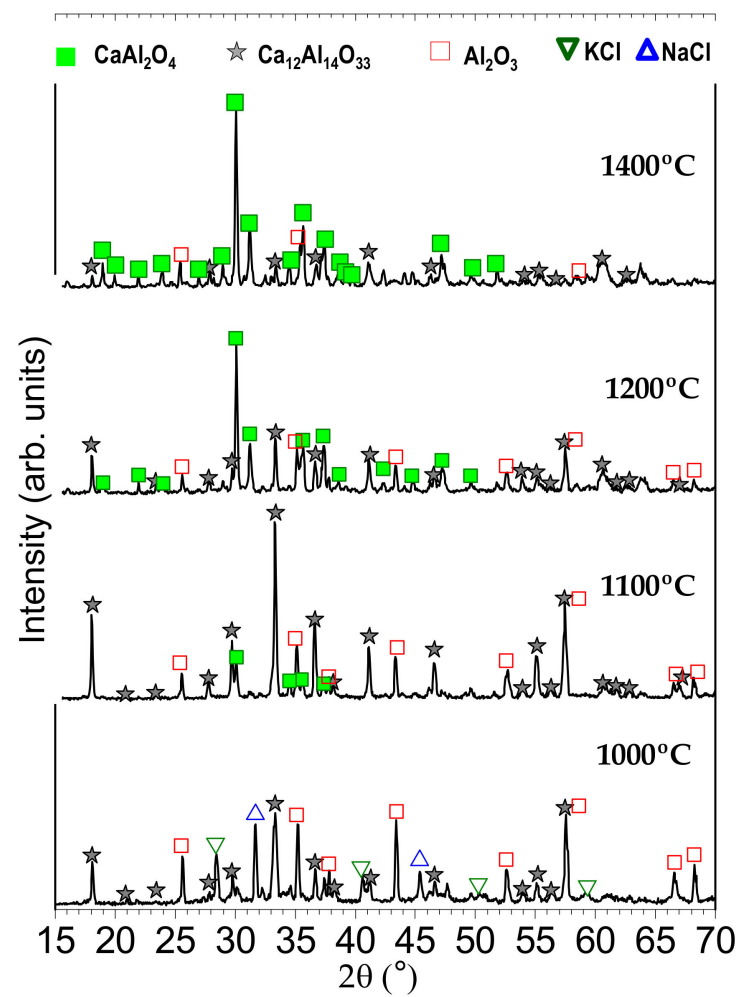

Figure 1. X-ray diffractograms (XRD) of synthesized calcium oxide $(\mathrm{CaO})$ : $\mathrm{Eu}, \mathrm{Nd}$ phosphor heated at $1000,1100,1200$ and $1400{ }^{\circ} \mathrm{C}$ for $2 \mathrm{~h}$ in air atmosphere, employing a salt/CAO molar ratio of 3:1. The symbols highlight aluminum oxide $\left(\mathrm{Al}_{2} \mathrm{O}_{3}\right)$ (red-open squares), sodium chloride $(\mathrm{NaCl})$ (blue-open triangles), potassium chloride $(\mathrm{KCl})$ (green-open triangles), monocalcium aluminate $\left(\mathrm{CaAl}_{2} \mathrm{O}_{4}\right)$ (green squares) and dodecacalcium hepta-aluminate $\left(\mathrm{Ca}_{12} \mathrm{Al}_{14} \mathrm{O}_{33}\right)$ (gray stars).

In order to obtain a phosphorescence response, europium and neodymium were incorporated as the dopants to synthesize $\mathrm{CAO}: \mathrm{Eu}^{2+}, \mathrm{Nd}^{3+}$ materials. The powders were thermally treated at 1000,1200 and $1400{ }^{\circ} \mathrm{C}$ for $2 \mathrm{~h}$ in a furnace under a nitrogen-hydrogen $\left(90 \mathrm{~N}_{2}-10 \mathrm{H}_{2}\right)$ atmosphere to reduce $\mathrm{Eu}^{3+}$ to $\mathrm{Eu}^{2+}$. As shown in Figure 2, the XRD pattern of the powder, which was thermally treated at $1000{ }^{\circ} \mathrm{C}$ for $2 \mathrm{~h}$, is similar to that annealed in air. In both cases the main phase is $\mathrm{Ca}_{12} \mathrm{Al}_{14} \mathrm{O}_{33}$. By contrast, under a reducing atmosphere, there is no residual salt revealed. Taking into account in the thermogravimetric (TG) analyses presented in detail elsewhere [12], the salt starts to vaporize above the m.p. $\left(659^{\circ} \mathrm{C}\right)$, and it is expected that the $100 \%$ weight loss of the eutectic mixture occurs at ca. $1010{ }^{\circ} \mathrm{C}$. However, the other components in the system can delay the total evaporation of the salt. During the thermal treatment of samples, a continuous gas flow of $90 \mathrm{~N}_{2}-10 \mathrm{H}_{2}$ at the pressure of $1 \mathrm{bar}$ is used in a tubular furnace.

Thus, it may be expected that the gas flow passing through the chamber promotes the dragging of the salt during the processing time, removing the remains of salt when $\mathrm{CaO}$ and $\mathrm{Al}_{2} \mathrm{O}_{3}$ are incorporated. At $1200{ }^{\circ} \mathrm{C}$, there is a coexistence of $\mathrm{Ca}_{12} \mathrm{Al}_{14} \mathrm{O}_{33}$ and $\mathrm{CaAl}_{2} \mathrm{O}_{4}$ phases with the minor amount of alumina $\mathrm{Al}_{2} \mathrm{O}_{3}$. Increasing the temperature up to $1400{ }^{\circ} \mathrm{C}$ results in the formation of the $\mathrm{CaAl}_{2} \mathrm{O}_{4}$ phase as a principal phase accompanying a trace amount of the $\mathrm{Al}_{2} \mathrm{O}_{3}$ phase. The crystallite size was also calculated; being 44(2), 55(3) and 63(3) nm for the samples synthesized at 1000, 1200 and $1400{ }^{\circ} \mathrm{C}$, respectively. As expected, the crystallite size increases as the sintering temperature increases, indicating that the crystallinity of the $\mathrm{CAO}$ phase is increased.

Therefore, the development of $\mathrm{Ca}_{12} \mathrm{Al}_{14} \mathrm{O}_{33}$ and $\mathrm{CaAl}_{2} \mathrm{O}_{4}$ phases by the molten salt route at 1000 and $1400{ }^{\circ} \mathrm{C}$, respectively, can be stated. Both polymorphs are the potential candidates to emit in the blue range conditioned by the successful incorporation of the doping elements. 


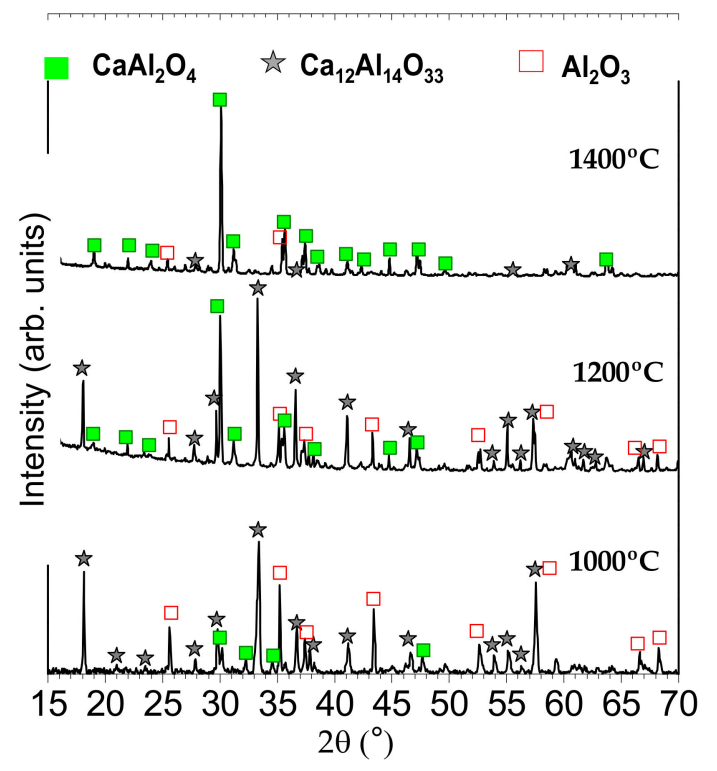

Figure 2. X-ray diffractograms of synthesized CAO: Eu, $\mathrm{Nd}$ phosphors heated at 1000, 1200 and $1400{ }^{\circ} \mathrm{C}$ for $2 \mathrm{~h}$ in $90 \mathrm{~N}_{2}-10 \mathrm{H}_{2}$, employing a salt/CAO molar ratio of 3:1. The symbols highlight $\mathrm{Al}_{2} \mathrm{O}_{3}$ (red-open squares), $\mathrm{CaAl}_{2} \mathrm{O}_{4}$ (green squares) and $\mathrm{Ca}_{12} \mathrm{Al}_{14} \mathrm{O}_{33}$ (gray starts).

\subsection{Effect of the Heat Treatment on the Morphology, and Particle Size Distribution}

Figure 3a-c depict the FE-SEM micrographs of the synthesized CAO particles, obtained from 1000 to $1400{ }^{\circ} \mathrm{C}$. The morphology of the platelet-like shaped alumina micro-particles is preserved at all temperatures of treatment. The alumina acts as a template, promoting the dissolution-diffusion transport mechanism of calcia and the rare-earth dopants by the eutectic nature of the salt mixture [12]. The procedure described allows synthesizing particles to possess a particle size in the micrometric range. Specifically, the particle size refers to the platelet-like shaped CAO microparticles. Due to the powder being not monodisperse, the particle size distribution describes the poly-dispersity character, reflecting the agglomeration state of these microparticles (see Figure $3 \mathrm{~d}-\mathrm{f}$, and Table 1). The microparticles are also nanostructured, and the synthesis of $\mathrm{CAO}: \mathrm{Eu}, \mathrm{Nd}$ occurs at the surface. The eutectic flux dissolves the $\mathrm{CaO}$ and transports this reactant to the surface of $\mathrm{Al}_{2} \mathrm{O}_{3}$. These platelets-like particles have a particle size smaller than $10 \mu \mathrm{m}$ for the samples synthesized at 1000 and $1200{ }^{\circ} \mathrm{C}$ and ca. $17 \mu \mathrm{m}$ for the sample obtained at $1400{ }^{\circ} \mathrm{C}$ that exhibits an additional formation of sintering necks between platelet particles through the $\mathrm{CAO}$ phase.

These nanostructured platelet-like particles are composed of grains or primary particles, which evolve as a function of the synthesis temperature as a consequence of the coalescence and grain growth process, as is shown in Figure 3 . At $1000^{\circ} \mathrm{C}$ the average grain size is ranged $100-500 \mathrm{~nm}$, and a second phase is located between the grains.

At $1200{ }^{\circ} \mathrm{C}$ the average grain size increases up to $800-1200 \mathrm{~nm}$, and in this case, the shape of the grains approaches straight grain boundaries and triple point junctions with $120^{\circ}$ indicating a near-equilibrium microstructure. However, the heat treatment at $1400{ }^{\circ} \mathrm{C}$ promotes the grain growth in each individual microparticle to get grains ranging from 1 up to $2 \mu \mathrm{m}$. The preferential growth occurs in the platelet plane because the thickness of the CAO platelets does not exceed $2 \mu \mathrm{m}$, which is a beneficial dimension for applications. As the main phase at a higher temperature is $\mathrm{CaAl}_{2} \mathrm{O}_{4}$, it is possible to correlate the grain growth in each individual microparticle with phase evolution. The crystallite size described in the previous section also increases as the sintering temperature increases, which is in good agreement with the tendency observed by FE-SEM (Figure 3). This indicates that the synthesized calcium aluminate phase $(\mathrm{CAO})$ at the alumina microparticle surface is composed of crystalline material, forming polycrystalline particles since the calculated crystallite sizes are considerably smaller than the observed average grain sizes. 
However, the presence of rare earth could play a relevant role in the nanostructure evolution. In this sense, the luminescence response will provide further pieces of evidence of the doping evolution and the micro-nano structure of each microparticle.

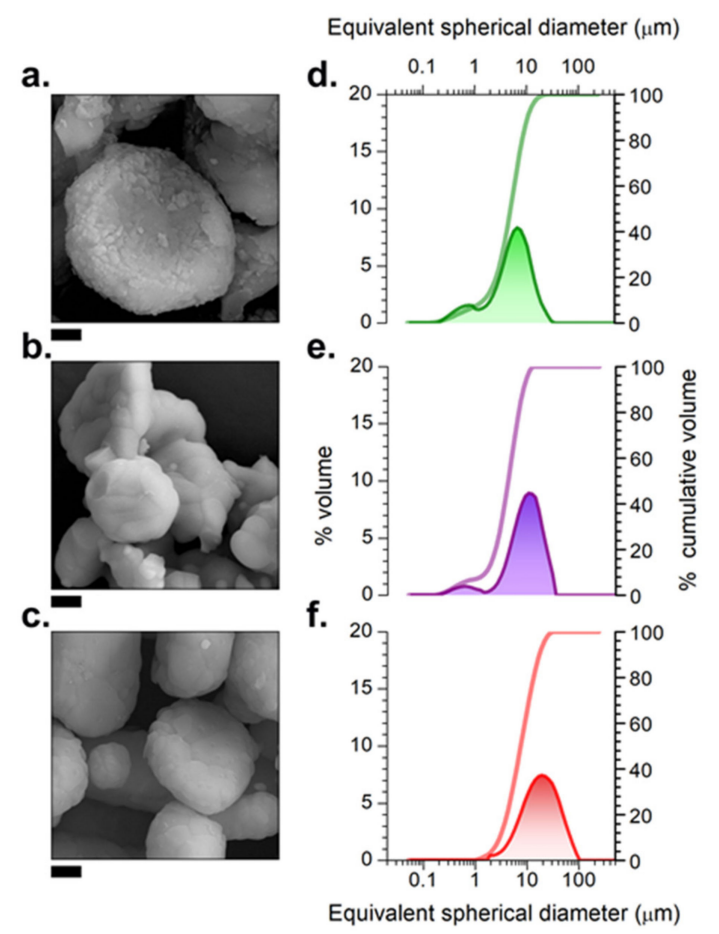

Figure 3. Field-emission scanning electron microscopy (FE-SEM) micrographs of the synthesized particles based on CAO: Eu, Nd phosphor heated at (a) 1000, (b) 1200 and (c) $1400{ }^{\circ} \mathrm{C}$ for $2 \mathrm{~h}$ in $90 \mathrm{~N}_{2}-10 \mathrm{H}_{2}$, employing a salt/CAO molar ratio of 3:1. Scale bars in panels (a) and (b) correspond to $1 \mu \mathrm{m}$, while in panels (c) they correspond to $2 \mu \mathrm{m}$. The particle size distribution of the particles synthesized at (d) $1000,\left(\right.$ e) 1200 and (f) $1400{ }^{\circ} \mathrm{C}$.

Table 1. Average particle size, $\mathrm{d}_{50}$, and $\mathrm{d}_{10}$ and $\mathrm{d}_{90}$ values of synthesized CAO: Eu, $\mathrm{Nd}$ phosphor heated at 1000,1200 and $1400{ }^{\circ} \mathrm{C}$ for $2 \mathrm{~h}$ in $90 \mathrm{~N}_{2}-10 \mathrm{H}_{2}$, employing a salt/CAO molar ratio of 3:1.

\begin{tabular}{cccc}
\hline & \multicolumn{3}{c}{ Particle Size } \\
\hline Sample & $\mathbf{d}_{\mathbf{1 0}}(\boldsymbol{\mu m})$ & $\mathbf{d}_{\mathbf{5 0}}(\boldsymbol{\mu m})$ & $\mathbf{d}_{\mathbf{9 0}}(\boldsymbol{\mu m})$ \\
\hline $1000^{\circ} \mathrm{C}$ & 2.6 & 7.8 & 18.1 \\
$1200^{\circ} \mathrm{C}$ & 2.9 & 8.8 & 19.0 \\
$1400{ }^{\circ} \mathrm{C}$ & 5.9 & 17.0 & 43.7 \\
\hline
\end{tabular}

\subsection{Photoluminescence Characterization and After Glow Properties}

Figure 4a shows the PL emission spectrum of the particles synthesized in the $\mathrm{N}_{2}-\mathrm{H}_{2}$ atmosphere. Eu dopant was incorporated as $\mathrm{Eu}_{2} \mathrm{O}_{3}$, in its trivalent oxidation state. Different techniques are described in the literature to reduce $\mathrm{Eu}^{3+}$ to $\mathrm{Eu}^{2+}$, and their stabilization is a non-trivial task. One possibility is to exploit the most commonly used $\mathrm{H}_{2}$ as a reduction agent. In our case, the annealing process carried out under a reductive atmosphere of $90 \mathrm{~N}_{2}-10 \mathrm{H}_{2}$ promotes the reduction of $\mathrm{Eu}^{3+}$ to $\mathrm{Eu}^{2+}$. Based on PL emission spectroscopy, it is straightforward to assess the presence of $\mathrm{Eu}^{2+}$ and $\mathrm{Eu}^{3+}$ emission centers. The $\mathrm{Eu}^{3+}$ emission is characterized by the narrow lines between 550 and $750 \mathrm{~nm}$ attributed to $4 \mathrm{f} \rightarrow 4 \mathrm{f}$ $\left({ }^{5} \mathrm{D}_{0} / \mathrm{F}_{\mathrm{j}}=0,1,2,3,4\right)$ transitions. As shown in Figure $4 \mathrm{a}$, the particles synthesized exhibit a broad emission band centered at $440 \mathrm{~nm}$ attributed to typical $4 \mathrm{f}^{6} 5 \mathrm{~d}^{1} \rightarrow 4 \mathrm{f}^{7}$ transitions of $\mathrm{Eu}^{2+}$ under the excitation at $365 \mathrm{~nm}$. A shift in the luminescence band position related to the $\mathrm{Ca}_{12} \mathrm{Al}_{14} \mathrm{O}_{33}$ phase synthesized at $1000{ }^{\circ} \mathrm{C}$ can be explained by a small change in the crystal field effect on the $\mathrm{Eu}^{2+}$ ions because of the 
splitting. It is important to remark that the emission peak attributed to the $\mathrm{Eu}^{2+}$ cations [17] transition becomes more intense with an increase in the temperature (from 1000 to $1400{ }^{\circ} \mathrm{C}$ ). The emission intensities are lower for the powder synthesized at $1000^{\circ} \mathrm{C}$, where the cubic phase $\mathrm{Ca}_{12} \mathrm{Al}_{14} \mathrm{O}_{33}$ is the predominant phase. At 1200 and $1400{ }^{\circ} \mathrm{C}$, the emission intensity further increases. At $1400{ }^{\circ} \mathrm{C}$, the single monoclinic phase of $\mathrm{CaAl}_{2} \mathrm{O}_{4}$ is steadily developed. As a first approach, the increment of the emission luminescence can be related to the phase composition. The inset in Figure 4a shows the excitation spectrum monitored at the $440 \mathrm{~nm}$ wavelength. This spectrum covers a broad spectral region from 273 to $418 \mathrm{~nm}$, assuming that the phosphor can be activated in this range. The standard solar spectrum (ASTM E-490) is presented to check that effectively a range of energies (UV-B and UV-A) of the solar irradiation spectrum can be used to stimulate the particles. It is known that the maximum fraction effectively used by Si solar cells [18] is lower than the maximum fraction available in this range. Therefore, the employment of $\mathrm{CAO}: \mathrm{Eu}, \mathrm{Nd}$ material on the top of the solar panel can serve as persistent storage. $[19,20]$ A comparison between the intensity obtained in CAO:Eu, $\mathrm{Nd}$ material and the commercial powder based on $\mathrm{SrAl}_{2} \mathrm{O}_{4}$ : Eu, Dy (from Jinan Chenghao Technology Co., Ltd., Mingshihaoting, NO.12406 Jingshi East Road, Jinan, 250014, China) as received is shown in the Supporting Information (Figure S1).

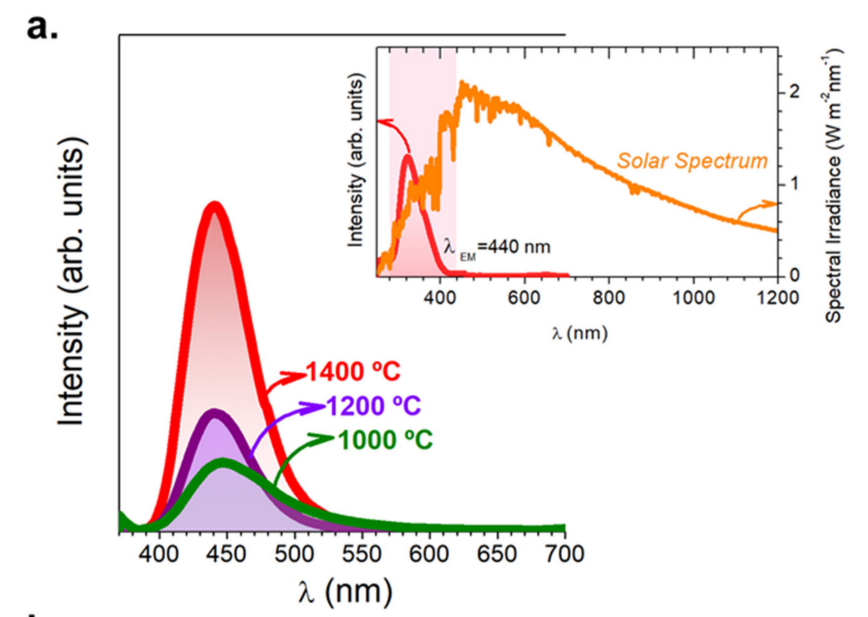

b.

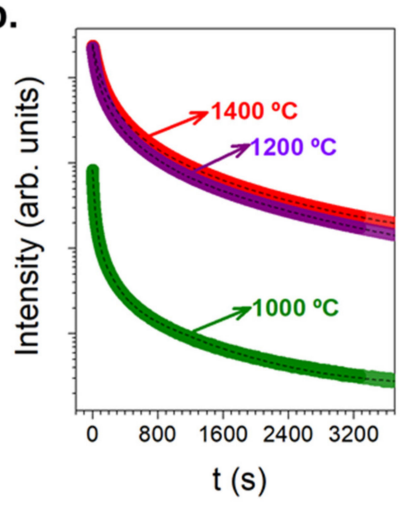

C.

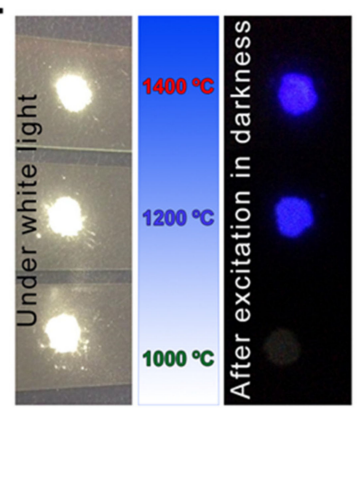

Figure 4. (a) Photoluminescence emission spectrum $\left(\lambda_{\mathrm{EXC}}=365 \mathrm{~nm}\right)$ of synthesized CAO: $\mathrm{Eu}, \mathrm{Nd}$ phosphors heated at 1000 (green line), 1200 (purple line), and $1400{ }^{\circ} \mathrm{C}$ (red-line) for $2 \mathrm{~h}$ in a $90 \mathrm{~N}_{2}-10 \mathrm{H}_{2}$ atmosphere, employing a salt/CAO molar ratio of 3:1. The inset shows the excitation spectrum fixing the emission at $440 \mathrm{~nm}$ (red-line) and the standard solar spectrum (American Society for Testing and Materials (ASTM) E-490) (orange line). (b) Afterglow decay curves of synthesized CAO: Eu, Nd phosphor heated at 1000 (green line), 1200 (purple line), and $1400{ }^{\circ} \mathrm{C}$ (red-line) for $2 \mathrm{~h}$ in $90 \mathrm{~N}_{2}-10 \mathrm{H}_{2}$, employing a salt/CAO molar ratio of 3:1 (c) Photographs of the CAO particles under white light excitation (left-image) and in dark after being activated for $10 \mathrm{~min}$ by a solar simulator (right-image). 
Besides the intense and broad photoluminescent emission, the CAO: Eu, Nd particles demonstrate a long-lasting luminescence after the stoppage of UV irradiation. The density of trapped carriers plays a key role in the enhancement of the afterglow duration. Specifically, co-doping with $\mathrm{Nd}^{3+}$ results in a higher density of trapped carriers as compared with other rare earths [4,21].

Therefore, to prolong the afterglow, there must be empty energy levels available at shallow as well as deep locations in the bandgap. By the molten salt synthesis proposed here, the host can hold the luminescent center introduced, creating the required and distributed empty defects to prolong the blue luminescence.

Measurements of the decay curve are one of the most useful ways to determine the duration of the luminescence. Figure $4 \mathrm{~b}$ shows the persistent luminescence with decay time lasting from $0 \mathrm{~s}$ to $3600 \mathrm{~s}$ (1 h). The CAO: Eu, Nd particles were excited for $10 \mathrm{~min}$, after that the excitation was cut off, and the afterglow curve was acquired. The profiles of the decay curves of the samples exhibit similar behavior. A multi-exponential decay profile was used to fit the experimental long afterglow decay data. Specifically, the observed afterglow decay curve was fitted by a quatri-exponential decay, following this equation:

$$
I=I_{1}+A_{1} \exp \frac{-t}{\tau_{1}}+A_{2} \exp \frac{-t}{\tau_{2}}+A_{3} \exp \frac{-t}{\tau_{3}}+A_{4} \exp \frac{-t}{\tau_{4}}
$$

where $I_{1}$ is the final intensity; $A_{1}, A_{2}, A_{3}$, and $A_{4}$ are constants; $t$ is the decay time; and $\tau_{1}, \tau_{2}, \tau_{3}$, and $\tau_{4}$ are fitting parameters related to the decay rate of the phosphors. The fitting parameters are given in Table 2.

The initial intensity of the sample thermally treated at $1000^{\circ} \mathrm{C}$ is lower, and the intensity drops two orders of magnitude compared with the samples annealed at $120{ }^{\circ} \mathrm{C}$ and $1400{ }^{\circ} \mathrm{C}$ for $1 \mathrm{~h}$. This behavior can be related to the phase composition obtained in each thermal treatment. The presence of the monoclinic polymorph phase of $\mathrm{CaAl}_{2} \mathrm{O}_{4}$ at $1200{ }^{\circ} \mathrm{C}$ and $1400{ }^{\circ} \mathrm{C}$ has more ability to store and release the energy in comparison with $\mathrm{Ca}_{12} \mathrm{Al}_{14} \mathrm{O}_{33}$. These four temporal processes may be related to different types of trap centers or different levels of the same trap species. As the persistent mechanism of CAO: $\mathrm{Eu}, \mathrm{Nd}$ is not yet established, to evaluate the decay rate of the fast $\left(\tau_{1}\right)$, rapid $\left(\tau_{2}\right)$, medium $\left(\tau_{3}\right)$ and slow $\left(\tau_{4}\right)$ exponential decay components, the steady-state contributions are quantified with $A_{i} \times \tau_{i}$ products ( $i=1$ to 4 ). $A_{i}$ represents the amplitude of the exponential decay and $\tau_{i}$, the lifetime [22]. These values are acquired from the numerical fits, and by these calculations, the fractional contribution of each component can be obtained, according to the following expression:

$$
I(t)=\sum_{i} A_{i} e^{-t / \tau_{i}}
$$

The fraction of each component in the multi-exponential decay is:

$$
S_{i}=\frac{A_{i} \cdot \tau_{i}}{\sum_{i} A_{i} \cdot \tau_{i}} \times 100
$$

Table 2. The fitting results of the decay parameters and the fractional contributions of the lifetime components (i.e., $\tau_{1}, \tau_{2}, \tau_{3}$, and $\tau_{4}$ ). $A_{1}, A_{2}, A_{3}$, and $A_{4}$ are constants, and $S_{1}, S_{2}, S_{3}$, and $S_{4}$ represent the $\%$ of each component.

\begin{tabular}{ccccccccccccc}
\hline Sample & $\boldsymbol{\tau}_{\mathbf{1}}(\mathbf{s})$ & $\boldsymbol{\tau}_{\mathbf{2}}(\mathbf{s})$ & $\boldsymbol{\tau}_{\mathbf{3}}(\mathbf{s})$ & $\boldsymbol{\tau}_{\mathbf{4}}(\mathbf{s})$ & $\mathbf{A}_{\mathbf{1}}$ & $\mathbf{A}_{\mathbf{2}}$ & $\mathbf{A}_{\mathbf{3}}$ & $\mathbf{A}_{\mathbf{4}}$ & $\mathbf{\% ~}_{\mathbf{1}}$ & $\mathbf{\%} \mathbf{S}_{\mathbf{2}}$ & $\% \mathbf{S}_{\mathbf{3}}$ & $\mathbf{\% ~}_{\mathbf{4}}$ \\
\hline $1000^{\circ} \mathrm{C}$ & 7.7 & 31.6 & 147.0 & 871.3 & 347281 & 328287 & 117781 & 27059 & 4.9 & 19.2 & 32,1 & 43.7 \\
$1200^{\circ} \mathrm{C}$ & 31.0 & 101.3 & 339.8 & 1386.5 & 9320400 & 8291800 & 3862010 & 1191890 & 7.1 & 20.5 & 32.0 & 40.4 \\
$1400^{\circ} \mathrm{C}$ & 61.2 & 216.3 & 735.2 & 3064.6 & 14081900 & 7358350 & 2473830 & 559904 & 14.4 & 26.6 & 30.4 & 28.7 \\
\hline
\end{tabular}

The contributions of medium $\left(\tau_{3}\right)$ and slow $\left(\tau_{4}\right)$ components have a higher weight in the decay process, which means that the persistence process is prolonged.

An important remark is that $\mathrm{CAO}: \mathrm{Eu}, \mathrm{Nd}$ white powders are obtained under indoor illumination following the molten salt procedure in comparison with the dark-gray color characteristic of these 
long-lasting materials. The origin of the dark-gray color, instead of white, in our material and in other oxides synthesized under the $\mathrm{N}_{2} / \mathrm{H}_{2}$ atmosphere, is attributed to the presence of oxygen vacancies in the structure [23]. (Left image in Figure 4c). The right image (Figure 4c) exhibits the response of the CAO: $\mathrm{Eu}, \mathrm{Nd}$ powders in darkness after cutting of the excitation.

\subsection{Tuning the Functional Properties by Heat Treatment and Eu2+ Content}

It is important to evaluate the intensity of the emission and a way to modulate it. As was previously shown, not only the crystallinity and the particle size are the parameters influencing the brightness. The fraction of the $\mathrm{Eu}^{2+}$ plays a key role in achieving higher intensities [23]. However, it is far from obvious to determine the fraction of both species from PL spectroscopy [23]. To do that, the XANES technique was employed, which can be considered as a powerful tool to investigate the valence states of the rare-earth dopants, i.e., europium. The significant difference in the absorption

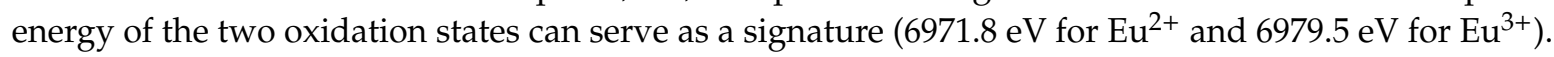

As Figure 5a depicts, an increase in the thermal temperature results in the domination of the absorption peak of the divalent Eu cations. It is worth it to remark that a considerable fraction of Eu ${ }^{3+}$ can be detected in the particles of $\mathrm{CAO}$, but the concentration is not reflected by the PL spectrum.
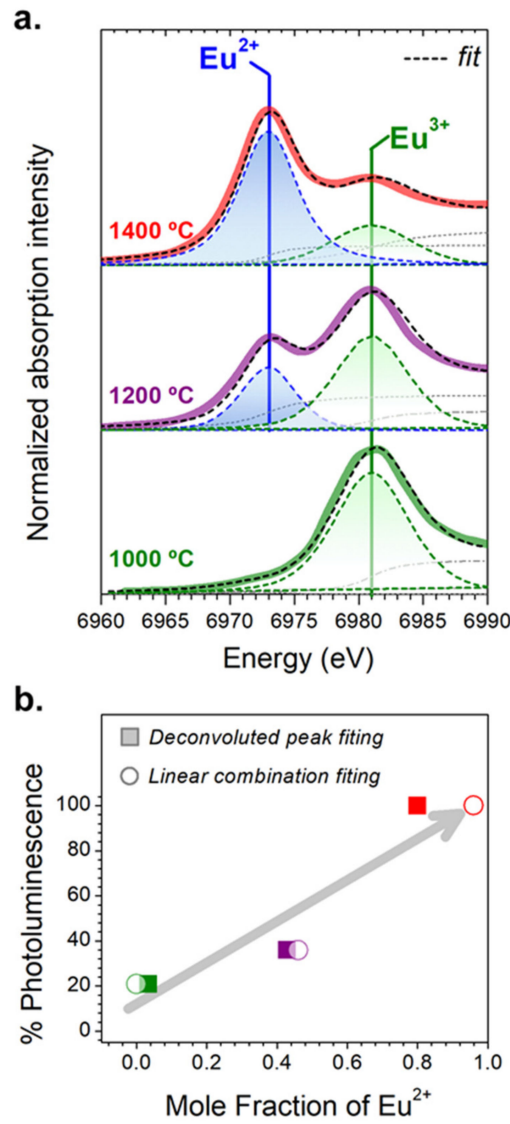

Figure 5. (a) X-ray absorption near-edge structure spectroscopy (XANES) measurements at the $\mathrm{Eu} \mathrm{L}_{3}$-edge of the particles synthesized at 1000 (green spectrum), 1200 (purple spectrum), $1400{ }^{\circ} \mathrm{C}$ (red spectrum). The fitting (black dashed curve) and the individual components (green and blue dashed curves) of the deconvoluted absorption peaks using pseudo-Voigt and arctangent step (gray dashed curves) functions are shown in the same graph. (b) \% of photoluminescence (PL) intensity of CAO particles synthesized at 1000 (green square and circle), 1200 (purple square and circle), $1400{ }^{\circ} \mathrm{C}$ (red square and circle) as a function of the $\mathrm{Eu}^{2+}$ fraction calculated by the deconvoluted peaks and by a lineal combination fitting. The \% PL intensity is referred to as the value obtained for the sample synthesized at $1400^{\circ} \mathrm{C}$. 
To determine the concentration ratio of $\mathrm{Eu}^{2+}$ and $\mathrm{Eu}^{3+}$ in the $\mathrm{CAO}: \mathrm{Eu}, \mathrm{Nd}$ particles, two methods were assessed. Several studies quantify the relative abundance of $\mathrm{Eu}^{2+}$ and $\mathrm{Eu}^{3+}$ ions in the samples by means of a linear combination fitting of standards at the $\mathrm{Eu}_{3}$-edge absorption. In this case, an absorption signal combination of $\mathrm{Eu}_{2} \mathrm{O}_{3}$ and $\mathrm{EuI}_{2}$ standards is performed using the Athena software. The fitting values for $\mathrm{Eu} \mathrm{L}$-edge XANES spectra analyzed by a linear combination of $\mathrm{Eu}_{2} \mathrm{O}_{3}$ and $\mathrm{EuI}_{2}$ references are compiled in Table 3. However, these analyses do not consider the transition probabilities of the two states $\left(2^{+}\right.$and $\left.3^{+}\right)$.

Previous studies suggest that the peak amplitude related to $\mathrm{Eu}^{2+} \mathrm{L}_{3}$-edge resonance is 1.5 times smaller than that corresponding to the $\mathrm{Eu}^{3+}$ resonance peak [24,25]. Taking this into account, the deconvoluted peak fitting of the white line (WL) at the $\mathrm{Eu} \mathrm{L}_{3}$-edge was done by using a pseudo-Voigt and an arctangent step function for each peak of the absorption spectra $[25,26]$ and employing the mole ratio $\mathrm{M}_{\mathrm{Eu}}$ through $\mathrm{M}_{\mathrm{Eu}}=\mathrm{RA}_{\mathrm{Eu}}[25,27]$. The $\mathrm{R}$-value is 1.5, and the $\mathrm{A}_{\mathrm{Eu}}$ represents the ratio between the $\mathrm{Eu}^{2+}$ and $\mathrm{Eu}^{3+}$ WLs. Figure $5 \mathrm{~b}$ shows the best fitting done by modeling the experimental data, and the results taking the reported transition probability difference are summarized in Table 4 . It should be noted that during the XAS experiments, no modifications in the average valence of the samples were identified by the $\mathrm{X}$-ray irradiation.

Table 3. Results of the linear combination fitting at the $\mathrm{Eu}^{2+}$ and $\mathrm{Eu}^{3+} \mathrm{L}_{3}$-edge WLs for the XANES spectra of the CAO: $\mathrm{Eu}, \mathrm{Nd}$ particles synthesized at 1000, 1200, $1400{ }^{\circ} \mathrm{C}$ for $2 \mathrm{~h}$ in a $90 \mathrm{~N}_{2}-10 \mathrm{H}_{2}$ atmosphere, employing a salt/CAO molar ratio of 3:1, alumina platelets with an average particle size $\mathrm{d}_{50 \sim} 6 \mu \mathrm{m}$, and using an $\mathrm{Al}_{2} \mathrm{O}_{3} / \mathrm{CAO}$ molar ratio of 1 .

\begin{tabular}{ccc}
\hline Sample & Species & Fraction \\
\hline \multirow{2}{*}{$1000{ }^{\circ} \mathrm{C}$} & $\mathrm{Eu}^{2+}$ & $0.00(2)$ \\
& $\mathrm{Eu}^{3+}$ & $1.00(2)$ \\
\hline \multirow{2}{*}{$1200{ }^{\circ} \mathrm{C}$} & $\mathrm{Eu}^{2+}$ & $0.54(3)$ \\
& $\mathrm{Eu}^{3+}$ & $0.46(3)$ \\
\hline \multirow{2}{*}{$1400{ }^{\circ} \mathrm{C}$} & $\mathrm{Eu}^{2+}$ & $0.96(4)$ \\
& $\mathrm{Eu}^{3+}$ & $0.04(1)$ \\
\hline
\end{tabular}

Table 4. Fitting results of $\mathrm{Eu}^{2+}$ and $\mathrm{Eu}^{3+} \mathrm{L}_{3}$-edge WLs from CAO particles synthesized at 1000, 1200, $1400{ }^{\circ} \mathrm{C}$ for $2 \mathrm{~h}$ in a $90 \mathrm{~N}_{2}-10 \mathrm{H}_{2}$ atmosphere, employing a salt/CAO molar ratio of 3:1, alumina platelets with an average particle size, $\mathrm{d}_{50 \sim} 6 \mu \mathrm{m}$, and using the $\mathrm{Al}_{2} \mathrm{O}_{3} / \mathrm{CAO}$ molar ratio of 1 by deconvoluted peak fitting using pseudo-Voigt and arctangent step functions.

\begin{tabular}{|c|c|c|c|c|c|c|c|c|c|}
\hline \multirow[b]{2}{*}{ Sample } & \multirow[b]{2}{*}{ Species } & \multicolumn{3}{|c|}{ Edge Resonance } & \multicolumn{3}{|c|}{ Edge Step } & \multirow[b]{2}{*}{ Fraction } & \multirow[b]{2}{*}{ R-Factor } \\
\hline & & Height Arb.u. & Position eV & FWHM & Area & Height Arb.u. & Position eV & & \\
\hline \multirow{2}{*}{$1000^{\circ} \mathrm{C}$} & $\mathrm{Eu}^{2+}$ & 0.45 & 6971.0 & 12.00 & 0.45 & 0.113 & 6971.0 & $0.03(1)$ & \multirow{2}{*}{0.00232} \\
\hline & $\mathrm{Eu}^{3+}$ & 19.70 & 6981.0 & 13.97 & 19.70 & 0.649 & 6981.0 & $0.97(1)$ & \\
\hline \multirow{2}{*}{$1200^{\circ} \mathrm{C}$} & $\mathrm{Eu}^{2+}$ & 6.128 & 6971.0 & 13.34 & 6.128 & 0.559 & 6971.8 & $0.43(1)$ & \multirow{2}{*}{0.00119} \\
\hline & $\mathrm{Eu}^{3+}$ & 12.29 & 6981.0 & 9.51 & 12.29 & 0.311 & 6979.5 & $0.57(1)$ & \\
\hline \multirow{2}{*}{$1400{ }^{\circ} \mathrm{C}$} & $\mathrm{Eu}^{2+}$ & 15.20 & 6971.0 & 9.88 & 15.20 & 0.319 & 6971.8 & $0.83(6)$ & \multirow{2}{*}{0.00150} \\
\hline & $\mathrm{Eu}^{3+}$ & 5.69 & 6981.0 & 14.54 & 5.69 & 0.572 & 6979.5 & $0.17(6)$ & \\
\hline
\end{tabular}

Despite the fact that from the linear combination fitting, the resulting $\mathrm{Eu}^{2+}$ percentage for the sample thermally treated at $1000{ }^{\circ} \mathrm{C}$ shows that $\mathrm{Eu}^{2+}$ is not present, the results obtained by the deconvoluted peak fitting and by PL spectroscopy reflect a low content of $\mathrm{Eu}^{2+}$. It means that in spite of XANES analysis exhibiting an insignificant fraction of $\mathrm{Eu}^{2+}$ cations, this quantity is enough to allow the blue emission of powder. In any case, further research is required to optimize the reduction process via the molten salt route, in order to increase the emission intensity. For samples prepared at $1200{ }^{\circ} \mathrm{C}$ and $1400{ }^{\circ} \mathrm{C}$, the $\mathrm{Eu}^{2+}: \mathrm{Eu}^{3+}$ fraction is calculated to be around 0.5:0.5 and 1:0, respectively, by both approaches, which agrees with the PL response. 
Figure $5 b$ exhibits the percentage of PL against the fraction of $\mathrm{Eu}^{2+}$ calculated from XANES spectra fitting by the deconvoluted peak and linear combination method. The relative amounts of $\mathrm{Eu}^{2+}$ determined by two fitting approaches show that the \% of PL, calculated for each sample, taking as $100 \%$ the PL intensity obtained for the sample sintered (frittage) at $1400{ }^{\circ} \mathrm{C}$, increases when the $\mathrm{Eu}^{2+}$ fraction increases, following a linear trend. Even so, the tendency is similar in both XANES fitting. The XANES results given from the fitting at the whiteline (WL), considering the transition probabilities of the two $\mathrm{Eu}^{2+}$ and $\mathrm{Eu}^{3+}$ states by the deconvoluted peak fitting or by the linear fitting of absorption signal with the $\mathrm{Eu}_{2} \mathrm{O}_{3}$ and $\mathrm{EuI}_{2}$ standards, provide the relative abundance of $\mathrm{Eu}^{2+}$ and $\mathrm{Eu}^{3+}$. This quantification cannot be assessed by taking into account only the results obtained by PL spectroscopy, showing that the joint characterization by both XANES and PL is necessary to evaluate and optimize the reduction of Eu species.

\section{Conclusions}

The reported method based on assisted molten salt flux evidences the production potential of the afterglow calcium alumina blue emitters. Analysis of the reaction mechanism confirms that the dissolution-diffusion transport process (template mechanism) prevails over the dissolution-precipitation mechanism. This novel approach proposed for the synthesis of the $\mathrm{Ca}_{12} \mathrm{Al}_{14} \mathrm{O}_{33}$ and $\mathrm{CaAl}_{2} \mathrm{O}_{4}$ phases doped with $\mathrm{Eu}$ and $\mathrm{Nd}$, controls the shape, morphology, and homogeneity of the platelets obtained. Overall, the micro-particles are individual ceramic particles composed of fully-sintered grains. The nanostructure of each micro-particle evolves with the synthesis temperature, favoring both the $\mathrm{CaAl}_{2} \mathrm{O}_{4}$ phase formation and the dopant incorporation into the structure. Remark that micro-particles are white in appearance, a fact that solves the problem of the dark gray coloring on aluminates synthesized in reducing atmospheres. Our observations demonstrate that persistent phosphors based upon calcium-aluminate compounds can be effectively activated by UV light and sunlight irradiation. The materials can work independently after being charged by artificial or solar light that is quite useful for practical applications. As regards the physical origin of the optical response, the results indicate that the control of the $\mathrm{Eu}^{2+} / \mathrm{Eu}^{3+}$ ratio (that is, find an optimal ratio of the chemical substituent) by suitable synthesis conditions is the key factor for enhancing the luminescence response. It is increasingly recognized that although calcium-aluminate systems have been studied extensively, the optimization of the Eu reduction by annealing conditions can open new paths in order to obtain the highest emission intensities.

Supplementary Materials: The following are available online at http://www.mdpi.com/2079-4991/9/10/1473/s1.

Author Contributions: The samples were prepared by R.E.R.-H. Characterization of the samples was performed by R.E.R.-H., F.R.-M., A.S., E.S., and J.F.F. F.R.-M. cooperated carefully on SEM characterization and analysis. R.E.R.-H. collaborated specifically on photoluminescence characterization and A.S., E.S. devotes the experience to XANES analysis. The manuscript was written by R.E.R.-H., edited by F.R.-M., A.S., E.S., I.H., and J.F.F., and approved by all authors. All authors contributed to discussions and reviewed the manuscript.

Funding: This work was supported by the Spanish Ministry of Science Innovation and Universities (MICIU) under the projects MAT2017-86450-C4-1-R and RTI2018-095303-A-C52, and the Spanish National Research Council (CSIC) under the project NANOMIND CSIC 201560E068. R.E.R.-H. acknowledges the financial support of the Mobilitas Pluss program in the framework of the MOBJD254 project. F.R.-M. is indebted to MINECO for a 'Ramon y Cajal' contract (ref: RyC-2015-18626), which is co-financed by the European Social Fund. F.R.-M. also acknowledges support from a 2018 Leonardo Grant for Researchers and Cultural Creators, BBVA Foundation. A.S. acknowledges the financial support from the Comunidad de Madrid for an "Atracción de Talento Investigador" contract (No. 2017-t2/IND5395). The support of ETAG through PUT1063 (I. Hussainova) is also acknowledged. We acknowledge the Spanish CRG BM25-SpLine, MICIU, CSIC and The European Synchrotron (The ESRF) for the use of the synchrotron radiation facilities, hospitality and financial help.

Conflicts of Interest: The authors declare no conflict of interest. 


\section{References}

1. Li, Y.; Gecevicius, M.; Qiu, J. Long persistent phosphors-From fundamentals to applications. Chem. Soc. Rev. 2016, 45, 2090-2136. [CrossRef] [PubMed]

2. $\mathrm{Xu}, \mathrm{J} . ;$ Tanabe, S. Persistent luminescence instead of phosphorescence: History, mechanism, and perspective. J. Lumin. 2019, 205, 581-620. [CrossRef]

3. Zhang, L.; Lyu, S.; Chen, Z.; Wang, S. Fabrication flexible and luminescent nanofibrillated cellulose films with modified SrAl2O4: Eu, Dy phosphors via nanoscale silica and aminosilane. Nanomaterials 2018, 8, 352. [CrossRef] [PubMed]

4. Katsumata, T.; Kubo, H.; Komuro, S.; Aizawa, H. Trap levels in Eu and other rare-earth ions codoped CaAl2O 4 phosphors. J. Am. Ceram. Soc. 2014, 97, 1704-1707. [CrossRef]

5. Qu, B.; Zhang, B.; Wang, L.; Zhou, R.; Zeng, X.C. Mechanistic study of the persistent luminescence of CaAl2O4:Eu,Nd. Chem. Mater. 2015, 27, 2195-2202. [CrossRef]

6. Kalita, J.M.; Chithambo, M.L. Temperature dependence of persistent luminescence in CaAl2O4:Eu2+,Nd3+ related to beta irradiation and optical excitation. J. Lumin. 2019, 206, 27-32. [CrossRef]

7. Aitasalo, T.; Holsa, J.; Lastusaari, M.; Niittykoski, J. Sol-gel processed Eu2+doped alkaline earth aluminates. J. Alloy. Compd. 2002, 341, 76-78. [CrossRef]

8. Chang, C.; Xu, J.; Jiang, L.; Mao, D.; Ying, W. Luminescence of long-lasting CaAl2O4:Eu2+,Nd3+ phosphor by co-precipitation method. Mater. Chem. Phys. 2006, 98, 509-513. [CrossRef]

9. Montes, P.J.R.; Valerio, M.E.G.; Rezende, M.D.S. Mechanisms of radioluminescence of rare earths doped $\mathrm{SrAl}_{2} \mathrm{O}_{4}$ and $\mathrm{Ca}_{12} \mathrm{Al}_{14} \mathrm{O}_{33}$ excited by X-ray. J. Electron Spectros. Relat. Phenom. 2013, 189, 39-44. [CrossRef]

10. Shi, C.; Zhu, Y.; Zhu, G.; Shen, X.; Ge, M. Phototunable full-color emission of dynamic luminescent materials. J. Mater. Chem. C. 2018, 6, 9552-9560. [CrossRef]

11. Rojas-Hernandez, R.E.; Rubio-Marcos, F.; Rezende, M.V.D.S.; Rodriguez, M.Á.; Serrano, A.; Muñoz-Noval, Á.; Fernandez, J.F. The impact of the synthesis conditions on SrAl2O4:Eu, Dy formation for a persistent afterglow. Mater. Des. 2016, 108, 354-363. [CrossRef]

12. Rojas-Hernandez, R.E.; Rubio-Marcos, F.; Gonçalves, R.H.; Rodriguez, M.Á.; Véron, E.; Allix, M.; Bessada, C.; Fernandez, J.F. Original Synthetic Route To Obtain a $\mathrm{SrAl}_{2} \mathrm{O}_{4}$ Phosphor by the Molten Salt Method: Insights into the Reaction Mechanism and Enhancement of the Persistent Luminescence. Inorg. Chem. 2015, 54, 9896-9907. [CrossRef] [PubMed]

13. Wang, L.X.; Xia, Q.; Kang, J.; Du, M.X.; Zhang, G.L.; Zhang, F.B. Measurement and correlation of solubilities of potassium chloride and potassium sulfate in aqueous glycerol solutions. J. Chem. Eng. Data 2011, 56, 3813-3817. [CrossRef]

14. Ravel, B.; Newville, M. ATHENA, ARTEMIS, HEPHAESTUS: Data analysis for X-ray absorption spectroscopy using IFEFFIT. J. Synchrotron Radiat. 2005, 12, 537-541. [CrossRef] [PubMed]

15. Kimura, T. Advances in Ceramics-Synthesis and Characterization, Processing and Specific Applications; Sikalidis, C., Ed.; IntechOpen: Rijeka, Croatia, 2011; pp. 75-100.

16. Chatterjee, A.K.; Zhmoidin, G.I. The phase equilibrium diagram of the system CaO-Al2O3-CaF2. J. Mater. Sci. 1972, 7, 93-97. [CrossRef]

17. Clabau, F.; Rocquefelte, X.; Jobic, S.; Deniard, P.; Whangbo, M.; Garcia, A.; Rouxel, J. Mechanism of phosphorescence appropriate for the Long-Lasting Phosphors $\mathrm{Eu}^{2+}$-doped $\mathrm{SrAl}_{2} \mathrm{O}_{4}$ with codopants $\mathrm{Dy}^{3+}$ and $\mathrm{B}^{3+}$. Chem. Mater. 2005, 17, 3904-3912. [CrossRef]

18. Huang, X.; Han, S.; Liu, X. Enhancing solar cell efficiency: The search for luminescent materials as spectral converters. Chem. Soc. Rev. 2013, 42, 173-201. [CrossRef]

19. Smet, P.F.; Van den Eeckhout, K.; De Clercq, O.Q.; Poelman, D. Chapter 274-Persistent Phosphors. In Handbook on the Physics and Chemistry of Rare Earths; Elsevier: Oxford, UK, 2015; pp. 1-108.

20. Van der Heggen, D.; Joos, J.J.; Rodríguez Burbano, D.C.; Capobianco, J.A.; Smet, P.F. Counting the photons: Determining the absolute storage capacity of persistent phosphors. Materials (Basel) 2017, 10, 867. [CrossRef]

21. Van den Eeckhout, K.; Bos, A.J.J.; Poelman, D.; Smet, P.F. Revealing trap depth distributions in persistent phosphors. Phys. Rev. B. Condens. Matter Mater. Phys. 2013, 87, 1-11. [CrossRef]

22. Lakowicz, J.R. Principles of Fluorescence Spectroscopy, 2nd ed.; Springer: New York, NY, USA, 2006; ISBN 0387312781. 
23. Avci, N.; Korthout, K.; Newton, M.A.; Smet, P.F.; Poelman, D. Valence states of europium in $\mathrm{CaAl}_{2} \mathrm{O}_{4}: \mathrm{Eu}$ phosphors. Opt. Mater. Express 2012, 2, 321. [CrossRef]

24. Rakovan, J.; Newville, M.; Sutton, S. Evidence of heterovalent europium in zoned llallgua apatite using wavelength dispersive XANES. Am. Mineral. 2001, 86, 697-700. [CrossRef]

25. Henke, B.; Palick, C.; Keil, P.; Johnson, J.A.; Schweizer, S. Eu oxidation state in fluorozirconate-based glass ceramics. J. Appl. Phys. 2009, 106, 113501. [CrossRef] [PubMed]

26. Brugger, J.; Etschmann, B.; Chu, Y.S.; Harland, C.; Vogt, S.; Ryan, C.; Jones, H. The oxidation state of europium in hydrothermal scheelite: In situ measurement by XANES spectroscopy. Can. Mineral. 2006, 44, 1079-1087. [CrossRef]

27. Antonio, M.R.; Soderholm, L.; Song, I. Design of spectroelectrochemical cell for in situ X-ray absorption fine structure measurements of bulk solution species. J. Appl. Electrochem. 1997, 27, 784-792. [CrossRef]

(C) 2019 by the authors. Licensee MDPI, Basel, Switzerland. This article is an open access article distributed under the terms and conditions of the Creative Commons Attribution (CC BY) license (http://creativecommons.org/licenses/by/4.0/). 